\begin{tabular}{|c|c|c|}
\hline $\begin{array}{l}\text { PKS } \\
\text { PUBLIC } \\
\text { KNOWLDGE } \\
\text { PROIICT }\end{array}$ & $\begin{array}{c}\text { REVISTA DE GEOGRAFIA } \\
\text { (RECIFE) } \\
\text { nttp://www.revistaufpe.br/revistageografia }\end{array}$ & 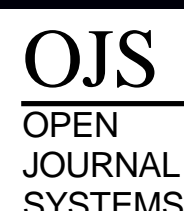 \\
\hline
\end{tabular}

\title{
A CARTOGRAFIA E AS CORRENTES DO PENSAMENTO GEOGRÁFICO
}

\author{
Ronaldo dos Santos Barbosa ${ }^{1}$, Francisco Kennedy Silva dos Santos ${ }^{2}$
}

\author{
${ }^{1}$ Professor do Curso de Geografia da Universidade Estadual da Região Tocantina do Maranhão. Email: \\ mestrando2005@hotmail.com \\ ${ }^{2}$ Professor do Departamento de Ciências Geográficas da Universidade Federal de Pernambuco. Email: \\ kennedyufpe@gmail.com
}

Artigo recebido em 23/12/2016 e aceito em 28/10/2017

\begin{abstract}
RESUMO
O presente artigo tem como objetivo destacar as contribuições que a cartografia trouxe para as correntes do pensamento geográfico. Trata-se de uma análise bibliográfica que aborda desde a geografia clássica à geografia contemporânea. Como forma de organização estruturou-se o artigo em três grandes matrizes epistemológicas e dentro de cada matriz identificou-se as correntes do pensamento geográfico e as contribuições da cartografia para cada uma delas. A primeira matriz identificada foi o positivismo que guiou a geografia tradicional e as correntes do determinismo, do possibilismo e do método regional. A segunda matriz foi o neopositivismo ou positivismo lógico que orientou a produção durante a chamada geografia nova e a última matriz que tem guiado a produção da geografia contemporânea, considerada por alguns pensadores como multiparadigmática, pois nela temos a geografia crítica orientada pelo materialismo dialético, a geografia humanística, cultural ou da percepção guiada pela fenomenologia e a geografia ambiental orientada pela visão sistêmica. No tocante a cartografia apresenta-se três correntes teóricas que tem guiado as pesquisas da área, a saber: a comunicação da informação cartográfica, a semiologia gráfica e cognição cartográfica.
\end{abstract}

Palavras-chave: Matriz Epistemológica, Paradigma, Pensamento Geográfico, Cartografia.

\section{THE CARTOGRAPY AND THE SCHOOLS OF GEOGRAPHY}

\begin{abstract}
The present article has as objective to highlight the contributions that the Cartography brought to the other schools of Geography. It is a bibliographic review which covers from classical to contemporary geography. As a method to organize the article, which is structured in three epistemological branches, it was identified in each branch the schools of the geographical thought and the contributions of cartography to each one of those schools. The first branch was the positivism, guide to the traditional geography, the approaches of determinism, possibilism and the regional method. The second branch was the post-positivism or logical positivism, which had guided scientific production during the period of the so-called new geography. The last branch, which has guided the contemporary geographical production, is considered by some scholars multi-paradigmatic, because it is based on it that we have the critical geography, driven by the dialectical materialism; the phenomenology of perception or the so-called humanistic or cultural geography; and the environmental geography, oriented by a systematic vision. In what concerns the cartography, we presented three theoretical branches that have been guiding researches in the field, which are: the communications of the cartographic information, the graphic semiology and the cognitive cartography.
\end{abstract}

Key-words: Ephistemological Branch, Paradigma, Schools of Geopgraphy, Cartography. 


\section{INTRODUÇÃO}

Analisar as correntes do pensamento geográfico e a cartografia não é tão fácil como aparenta, principalmente se tratando de uma análise puramente bibliográfica, pois as obras consultadas não dão ênfase ao uso da cartografia no tratamento das informações espaciais.

Diversas áreas do conhecimento utilizam-se do mapeamento para representar e analisar a distribuição espacial de objetos e fenômenos, contudo, o mapeamento é atividade compreendida principalmente pela Geografia e pela Cartografia. Com a diversificação e ampliação dos conteúdos e técnicas de mapeamento, a Cartografia conquistou status de disciplina independente, o que resultou na especialização das atribuições do mapa e do mapeamento na Geografia e na Cartografia. O espaço, embora concebido de forma diferente, está presente nas preocupações dessas duas ciências.

$\mathrm{Na}$ Geografia ele é considerado objeto principal de análise e o seu mapeamento é parte do processo investigativo e comunicativo. Como afirma Douglas Santos (2002), o mapa é parte do discurso geográfico. Para a Cartografia, o espaço é fonte de informações para o seu objeto de estudo - o mapa. Neste sentido, na Cartografia a ênfase está em levantar e representar as informações primárias do espaço e descobrir melhores formas para esta tarefa.

Enquanto a preocupação da Cartografia está na representação, e ai o mapa é o fim, a Geografia se preocupa com o uso do mapa na análise do espaço geográfico, e para isso o mapa é um meio. Todos os mapas são de interesse do geógrafo e do cartógrafo, porém, esses dois profissionais possuem habilidades e objetivos diferentes no que diz respeito à sua condição de mapeador e/ou utilizador do mapa (ARCHELA e ARCHELA, 2002).

$\mathrm{O}$ presente trabalho tem como objetivo identificar as características das principais correntes do pensamento geográfico e destacar as contribuições que a cartografia trouxe para tais correntes. Trata-se de uma pesquisa bibliográfica, onde analisou-se tanto autores clássicos quanto contemporâneos.

Parte-se, portanto, de uma análise auto-reflexiva do 'lugar' da Cartografia no cenário da discussão histórico-temporal das Correntes do Pensamento Geográfico, respaldados em pesquisas tipo "estado da arte" ou "estado do conhecimento" de caráter bibliográfico para dar suporte a nossas intervenções (BRZEZINSKI e GARRIDO, 1999; FERREIRA, 2002; THERRIEN e NÓBREGA-THERRIEN, 2004). A realização de estados da arte possibilita a efetivação de balanço da pesquisa de uma determinada área de conhecimento e podem significar uma contribuição importante na constituição de seu campo teórico, pois procuram 
identificar os aportes significativos da construção da teoria e prática, elucidando as possíveis lacunas e ao mesmo tempo revelando experiências inovadoras investigadas que apontem alternativas de solução para os problemas da prática e reconhecimento das contribuições da pesquisa na constituição de propostas na área focalizada

O trabalho foi desenvolvido a partir de três matrizes ${ }^{1}$ epistemológicas a saber, positivismo, neopositivismo e a matriz contemporânea que engloba vários paradigmas. Dentro de cada matriz serão abordadas as correntes do pensamento geográfico do determinismo, passando pelo possibilismo, método regional, geografia quantitativa, geografia crítica, humanística e ambiental, paralelo a isso o destaque para a contribuição da cartografia na leitura do objeto da geografia. Com relação ao marco temporal teremos como ponto de partido o final do século XIX até os dias atuais.

\section{A GEOGRAFIA CLÁSSICA E A MATRIZ POSITIVISTA}

As pesquisas e estudos desenvolvidas no período da chamada Geografia Tradiciaonal tiveram como base teórico-metodológica o positivismo. Foi uma geografia pautada na observação e descrição de fatos, que se dividiu em duas correntes, a saber: o Determinismo alemão e o Possibilismo francês. Moraes (1983) cita que a organização da geografia científica ocorreu sobre as bases do positivismo e foi nesta concepção filosófica e metodológica que os geógrafos foram buscar as orientações para o desenvolvimento de seus estudos. Para o positivismo, os estudos devem restringir-se ao visível, real, mensurável e palpável; como se os fenômenos se demonstrassem diretamente ao cientista, que seria um simples observador (ANDRADE, 1989).

Segundo Moraes (2003), o positivismo leva à redução da realidade ao mundo dos sentidos e com base nele os trabalhos científicos foram desenvolvidos a partir da aparência dos fenômenos. Nesta corrente teórica predomina a máxima de que a "Geografia é uma ciência empírica, pautada na observação". A descrição, enumeração e classificação dos fatos foram os procedimentos aos quais a Geografia Tradicional se limitou.

Em nossa busca por bases teórico-metodológicas sobre as evidências das contribuições da cartografia nas correntes do pensamento geográfico, constatamos que a produção da

\footnotetext{
${ }^{1}$ Matrizes são as formas de pensamento que partem de um núcleo racional por meio do qual uma estrutura global emerge como discurso de mundo, uma estrutura matricial se distinguindo da outra justamente pela maneira como o intelectual vê e interliga o mundo (MOREIRA, 2008, p. 47).
} 
geografia brasileira é deficitária a este respeito, sendo o mapa e o mapeamento negligenciados na grande maioria das obras publicadas. Esta situação é resultado da difusão da Geografia Crítica como corrente teórica predominante no Brasil, pois esta corrente, no movimento de renovação da Geografia, associou o uso do mapa e do mapeamento unicamente aos objetivos e análise das correntes Tradicional e Pragmática, o que não é correto.

Assim como um texto, o mapa transmite a visão de mundo de seu autor e é, por excelência, parte do discurso geográfico e instrumento da análise geográfica. Trataremos a seguir das correntes que integram esta matriz epistemológica.

\section{A CORRENTE DO DETERMINISMO AMBIENTAL}

O determinismo enquanto corrente do pensamento geográfico surge final do século XIX na Alemanha, tendo Friedrich Ratzel como idealizador. A concepção que Ratzel tinha de Geografia foi herda em parte de Humboldt e Ritter, porém estruturada numa visão darwinista (CLAVAL, 2006). A corrente do determinismo aborda as contribuições das condições naturais determinantes no comportamento do homem. Pelo fato de Ratzel apoiar suas análises na visão darwinista, ele procurou entender a difusão dos povos pela superfície terrestre, problemática que, segundo ele, articularia história, etnologia e geografia em uma mesma discussão (MOREIRA, 2008).

Para o determinismo as diferentes formas de organização do espaço e as desigualdades existentes eram explicadas pelas condições ambientais em especial as climáticas.

\footnotetext{
Na geografia, no entanto, as ideias deterministas tiveram no geógrafo alemão Ratzel seu grande organizador e divulgador, ainda que ele não tivesse sido o expoente máximo. A formação básica de Ratzel passou pela zoologia, geologia e anatomia comparada; foi aluno de Haeckel, o fundador da ecologia, que o introduziu no darwinismo (CORRÊA, 1995, p. 10).
}

Para entender melhor o determinismo é importante analisar o contexto do período. Corrêa (2003) aponta que o determinismo foi o primeiro paradigma a caracterizar a Geografia no século XIX, em razão da passagem do capitalismo de sua fase comercial para a fase monopolista. Segundo o autor o determinismo foi amplamente utilizado para justificar o processo de expansão nos continentes africano e asiático.

Embora não seja possível identificar nas obras dos autores consultados, tópicos específicos tratando do uso da cartografia nesta corrente, pose fazer constatações em função das características comuns que matriz do positivismo empregava nos estudos científicos do 
período que se limitava a descrição dos espaços estudados, baseados nas observações empíricas.

A produção dos mapas na geografia determinista eram fruto de dados de distância de viagens, de contorno de litoral e de pontos de referência. A determinação e a exposição dos aspectos espaciais da realidade por meio de mapeamento foram de importância fundamental (PATTISON, 1977).

\section{A CORRENTE DO POSSIBILISMO GEOGRÁFICO}

A segunda corrente de que trata este artigo surge no final do século XIX na França, tendo Paul Vidal de La Blache como idealizador. Nesta corrente considera-se a natureza fornecedora de possibilidades para que o homem a modificasse. $\mathrm{O}$ homem é o principal agente geográfico. Na França La Blache passou a estudar profundamente a geografia desenvolvida pelos alemães, principalmente os trabalhos de Ratzel, para quem dedicou profundas críticas (MOREIRA, 2008).

Assim, La Blache desenvolveu outra concepção da relação "homem-meio", na qual passou a pensar a possibilidade que o homem tem de superar as imposições naturais, dependendo do nível cultural, das condições técnicas e da disposição de recursos, podendo, dessa forma, atuar sobre a natureza e modifica-la. Em uma área fisicamente delimitável eram integrados e descritos, tantos os aspectos físicos, como os humanos/sociais e econômicos, dando origem ao Possibilismo (MORAES, 2003).

Corrêa, (1986) aponta que o Possibilismo, francês em sua origem, opõe-se ao determinismo ambiental germânico. Esta oposição fundamenta-se nas diferenças entre os dois países. Vale a pena ressaltar que a competitividade existente entre França e Alemanha, acirrou-se com a perda da região francesa da Alsácia-Lorena para a Prússia durante a guerra franco-prussiana (ANDRADE, 1989).

Utilizado nas escolas de Humboldt, Ritter e Ratzel, o mapa ganha destaque ainda maior com Vidal de La Blache, juntamente com as tipologias. Os estudos consistiam em um levantamento cartográfico inicial e "a conclusão em geral constituída por um conjunto de cartas, cada uma referente a um capítulo, as quais sobrepostas dariam relações entre os elementos da vida regional." (MORAES, 2003, p.78). Através da influência da proposta de La Blache, Max Sorre propõe uma metodologia de pesquisa geográfica que: 
[...] partia da Cartografia: a ideia de uma sobreposição de dados da observação, em um mesmo espaço, analisando historicamente a formação de cada elemento desde os naturais (solo, vegetação etc.) até os sociais (hábitos alimentares, religião etc.). Assim, se chegaria a compor, por sobreposição das informações, um quadro de situação atual, e aí se estudaria seu funcionamento, inter-relacionando os elementos presentes. (MORAES, 2003, p.81).

Observa-se que a partir do possibilismo a cartografia começa a fazer parte dos geográficos, facilitando assim uma abordagem mais completa da realidade. Pois a partir da espacialização das informações era possível fazer generalizações com mais evidências.

\section{A CORRENTE DO MÉTODO REGIONAL}

A terceira corrente de matriz positivista, conhecida como método regional, opõe-se às duas correntes antecedentes, visto que a diferenciação de áreas não é vista a partir das relações entre o homem e a natureza, mas sim da integração de fenômenos heterogêneos em uma dada porção da superfície da Terra, portando esta corrente esta vinculada ao estudo de áreas e regiões. Segundo Corrêa (1986) o método regional já vinha sendo estudado desde o século XVII por Varenius passando por Kant no século XVIII e por Ritter no século XIX. Essa corrente de pensamento corroborava a necessidade de se produzir uma geografia regional, isto é, um conhecimento resumido sobre as diferentes áreas globais.

Surge com maior força no início do século XX a partir da década de 1930 nos Estados Unidos. Tendo Richard Hartshorne como grande ícone desta corrente. Em 1936, Hartshorne procurou trabalhar o conceito de "unidade-área" como uma parte do espaço geográfico definida pelo pesquisador em função do objeto de estudo e da escala de trabalho, cujo objetivo era a demonstração de áreas como características individuais próprias. Dai o autor propõe duas formas de abordagem, uma denominada como Geografia Idiográfica e a outra, Geografia Nomotética.

Mormul e Rocha (2013) apontam que para Hartshorne as várias partes do campo da Geografia, tais como Geografia física, Geografia política e Geografia econômica foram apontadas para o tratamento especial, isto influenciado pela geografia alemã, ela considerou que a geografia se constituía enquanto ciência concreta desde que em primeiro lugar busca-se compreender e explicar o mundo, todavia sem desconsiderar a descrição das totalidades como um produto do conhecimento geográfico. Neste sentindo esta nova corrente procurou superar os limites da escola francesa bem como do determinismo geográfico. 
Rodrigues (2008) afirma que foi Hartshorne quem articula a Geografia Geral e Regional diferenciando-as pelo nível de profundidade das inter-relações dos elementos estudados, quanto menor o número de elementos inter-relacionados, maior a possibilidade de generalização; quanto maior o número de elementos inter-relacionados, mais profunda a análise, maior o conhecimento da singularidade da "área", maior a possibilidade de estudo regional.

Já Christofoletti (1985) explica que o método regional considerava que cada categoria de fenômeno era objeto de determinada ciência e que caberia a estas ciências executarem as análises sobre os assuntos particulares. À Geografia, considerando a totalidade, correspondia o trabalho de síntese, reunindo e coordenando todas as informações a fim de salientar a visão global da região ou área estudada.

A ampla utilização dos mapas na Geografia Tradicional, trazida para o Brasil pelos principalmente pelos franceses, é fruto do processo de sistematização da disciplina e do momento histórico dos seus fundadores. A busca pelo aperfeiçoamento das técnicas cartográficas foi constante na Geografia Tradicional, para a qual "o próprio desenvolvimento das técnicas de descrição e representação também foi um saldo favorável." (MORAES, 2003, p.91). A concepção de espaço estava ligada ao mapeável. Os levantamentos de informações tinham como destino o mapeamento e o cruzamento das informações era realizado através dos mapas. Geografia e mapa eram indissociáveis para os pesquisadores desta corrente.

\section{A NOVA GEOGRAFIA E A MATRIZ NEOPOSITIVISTA}

A segunda matriz epistemológica da Geografia começa a ser construída a partir de meados da década de 1970 momento em que ocorre o processo de renovação da Geografia, principalmente por que as fundamentações e o instrumental da Geografia Tradicional não conseguiam explicar as mudanças ocorridas na realidade pelo desenvolvimento do capitalismo.

A Geografia Pragmática ou Nova Geografia ou ainda Geografia Quantitativa está baseada no neopositivismo, realiza uma crítica à incapacidade da Geografia Tradicional em explicar a realidade e às características não práticas (observação e descrição) de seus estudos. O objetivo principal desta nova corrente é criar uma tecnologia geográfica. As análises são baseadas em dados e o uso de modelos é amplo e o trabalho de campo é negligenciado em detrimento da análise indireta. (MORAES, 2003). 
Compõem o conjunto metodológico da Geografia Pragmática o tratamento estatístico dos dados, o uso do computador, do sensoriamento remoto e do mapeamento automático, principalmente na elaboração de tipologias. O uso do mapa e dos procedimentos de mapeamento são ainda mais intensos na Geografia Pragmática, pois o advento do computador possibilitou trabalhar com mais agilidade e com um volume maior de dados. O processo de mapeamento se tornou mais rápido, aumentando as possibilidades de produção e reprodução de mapas. De acordo com Moraes (2003) e Fernandes (1999) as principais críticas feitas a esta corrente teórica estão direcionadas ao distanciamento da realidade através de sua matematização.

\section{A CORRENTE DA GEOGRAFIA TEORÉTICA E QUANTITATIVA}

Esta corrente surge no século XX a partir da década de 1950 na Inglaterra, Suécia e Estados Unidos. A mesma recebe várias nominações como: Geografia quantitativa, Geografia teorética, Nova geografia. Tinha como destaque o uso da matemática, da informática e da estatística. Claval (2006) cita que a partir da década de 1950, a renovação da geografia provém cada vez mais dos programas desenvolvidos nas universidades dos EUA, da GrãBretânia e, em menor medida, do Norte da Europa. Isso deve-se ao papel crescente do mundo anglo saxônico em todos os domínios da vida internacional, incluindo as ciências.

Os geógrafos esperam encontrar uma ordem no mundo real. Para a descobrirem prontificam-se a confiar nas matemáticas: estas evoluíram e estão mais preparadas do que no início do século para evidenciar as subtilezas das realidades sociais. A melhoria dos procedimentos de cálculo torna mais fácil o emprego de algoritmos até então considerados demasiado complexos. Esta mutação é importante para os geógrafos. As séries corológicas que lhe interessam são tão difíceis de tratar que a única maneira de tirar partido delas é cartografá-las. Os meios de cálculo tornam possível a decomposição das séries nas suas componentes principais: em vez de acumular mapas redundantes, retém-se apenas a informação significativa (CLAVAL, 2006).

Christofoletti (1985) explica que a Geografia quantitativa se caracterizou pelo maior rigor na aplicação da metodologia científica embasada no neopositivismo, no uso de técnicas de estatística e matemática, na abordagem sistêmica e no uso de modelos. Santos (1986) aponta que a Nova Geografia se manifestou sobretudo, através da quantificação e da abordagem sistêmica, para o autor a quantificação ocorreu em razão da procura de uma 
linguagem matemática que desse cientificismo à Geografia. Corrêa (2003) cita que o emprego de técnicas estatísticas como: média, desvio padrão, coeficiente de correlação, entre outros foram muito utilizados nos estudos geográficos no período.

A nova geografia física caracteriza-se, sobretudo, pelo recurso sistemático às simulações de laboratórios, a experimentação e aos métodos matemáticos: estas orientações favorecem dois ramos especializados, a geomorfologia e a climatologia dinâmica.

A década de 1970 fica marcada como o período de grandes mudanças nas ciências humanas e sociais. Na cartografia estas mudanças são identificadas com a criação de vários modelos de comunicação da informação cartográfica, desenvolvimento industrial nos Estados Unidos. Inicialmente este movimento é percebido em âmbito internacional e posteriormente no Brasil. Archela e Archela (2002) apontam que em âmbito internacional pode-se destacar as contribuições do Soviético K. A. Salichtchev, dos Americanos A. H. Robinson, B. B. Petchenik e J. L. Morrison, do Polonês L. Ratajski, do Holandês C. Koeman e do Eslovaco A. Kolacny.

Sob este enfoque teórico o mapa é considerado um veículo de informação. O desenvolvimento máximo desta teoria cartográfica foi atingido por Kolacny (1969), para ele, a cartografia é definida como teoria, técnica e prática de duas esferas de interesses: a criação e o uso de mapas. Seu modelo de comunicação cartográfica inspirou pesquisas e debates posteriores. No Brasil, Simielli (1986) analizou exaustivamente todos os modelos de comunicação apresentados até aquele momento e avaliou o mapa como meio de transmissão de informação.

Embasado nesta teoria, Libault (1971) propôs um roteiro de investigação com base essencialmente cartográfica, que consiste nos níveis compilatório, correlatório, semântico e normativo. A modelização cartográfica como base teórica, foi introduzida no Brasil na década de 1970, especialmente nos trabalhos do IBGE, nas pesquisas desenvolvidas pela UNESP de Rio Claro e pela UFRJ.

\section{A GEOGRAFIA CONTEMPORÂNEA E SEUS PARADIGMAS}

Este período podemos caracterizar como o surgimento da geografia contemporânea. Para Correa (2011) a contemporaneidade é entendida como o tempo presente que se estende de aproximadamente 1970 aos dias atuais. O autor afirma que trata-se de um período denso, no qual ocorre um combinação de características que o distingue dos períodos que o 
antecederam ou que irão ocorrer. Neste sentido para atender as características da geografia contemporânea um só paradigma não daria conta de fazer a leitura da realidade, dai uma das características principais do momento é marcada pela pluralidade de paradigmas.

Por paradigma entende-se o conjunto de ações intelectuais que possibilitam estabelecer uma dada inteligibilidade à realidade, com base em conexões de ideias de natureza descritiva, explicativa, normativa, preditiva ou compreensiva. Nesta conexão estão diferentes relações entre sujeito do conhecimento e objeto do conhecimento. Das conexões emergem também problemáticas, questionamentos, e os procedimentos operacionais. Um paradigma tem uma vertente teórico-conceitual e outra metodológica, tratando-se, em realidade, de uma matriz intelectual. Um paradigma não leva, conteúdo, à seleção de alguns temas e à exclusão de outros, pois cada tema é passível de ser abordado por mais de um paradigma, ainda que preferências temáticas tenham sido estabelecidas no âmbito de um dado paradigma. A reclusão de um tema em um único paradigma é um equívoco, derivado da adoção de uma visão reducionista, seja qual for o paradigma considerado (CORRÊA, 2011).

A necessidade de vários paradigmas para dar conta da leitura do espaço geográfico se justifica quando Moreira (2008) coloca que a crise do paradigma fragmentário se evidencia no decorrer dos anos 1960-1970. Embora se possa datar a nova fase dos anos 1960, é na década de 1970 que o surgimento aparece com mais evidência. O autor traça um panorama da geografia neste período e descreve novas tendências surgidas com a crise do pensamento geográfico.

É nessa década que a crise do paradigma fragmentário e físico-matemático se mostra mais visível, seja pela exacerbação do modelo, na forma da geografia teoréticoquantitativa (Corrêa, 1982), seja pela emergência de novas linhas teóricometodológicas, na forma de uma geografia de referência no marxismo, no subjetivismo e num ambientalismo de novo tipo. Mais recentes, e podendo-se dizer ainda nos seus primeiros ensaios, são as correntes que se referenciam na filosofia da linguagem de Ludwig Wittgenstein e Mikail Bakthin e na filosofia da complexidade de Edgar Morin, Esabelle Stengers e Henri Atlan (MOREIRA, 2008, p. 39).

No entanto, para este artigo abordaremos apenas a geografia crítica apoiada no materialismo dialético, a geografia humanística ancorada na fenomenologia e a geografia ambiental que tem usado a visão sistêmica como eixo norteador de suas pesquisas, tentando identificar o papel da cartografia nestas correntes ao longo das duas últimas décadas do século passado e na primeira década deste século. 


\title{
A GEOGRAFIA CRÍTICA E O PARADIGMA DIALÉTICO
}

No período pós Segunda Guerra Mundial se iniciou o movimento de renovação do pensamento geográfico. Isso se deu em função das condições sociais em que o mundo se encontrava, com sérios problemas de pobreza, desigualdades sociais, fome e conflitos localizados. Santos (1986) coloca que a Geografia não podia escapar às enormes transformações ocorridas em todos os domínios científicos após 1950.

No campo das ciências as modificações vivenciadas neste período eram principalmente inerentes às novas tecnologias desenvolvidas, levaram inúmeros pesquisadores a refletir a busca de novas possiblidades teórico-metodológicas. Século XX a partir da década de 1970 na França e Brasil. Tendo Yves Lacoste e Milton Santos.

\begin{abstract}
O pensamento marxista chega à geografia nos anos 1970, e em diferentes cantos do mundo. Nos anos 1950 um grupo de geógrafos de que fizeram parte Jean Tricart, Pierre George, René Guglielmo, Jean Dresch e Bernard Kayser e ainda podemos acrescentar Yves Lacoste, buscam criar na França uma geografia fundada no materialismo histórico e dialético, que entretanto, pouco avança nesse intento. Nos anos 1970, é a vez de um nipe de geógrafos, espalhados por vários países, como David Harvey e Edward Soja nos Estados Unidos, Milton Santos e Armando Corrêa da Silva no Brasil, Yves Lacoste na França e Massimo Quani na Itália, trazer de volta a relação entre marxismo e geografia, fazendo dessa vez ir mais fundo o mergulho cruzado que ficara no meio do caminho com os geógrafos franceses (MOREIRA, 2008, p. 40).
\end{abstract}

A Geografia brasileira contemporânea, pela grande influência da Geografia Crítica, negligencia o mapa como instrumento da análise geográfica e como parte do discurso geográfico. Para entender melhor a atual situação do mapa na Geografia brasileira, é necessário analisar seu papel nas correntes geográficas tradicional, pragmática e crítica (GIRARDI, 2008).

As influencias que a geografia critica teve sobre o não uso do mapa são perceptíveis não só nas pesquisas mais também no ensino. Sousa e Katura (2001) relatam que boa parte dos professores formados sob a égide da Geografia Crítica, não utilizam o mapa em sala de aula, seja por não possuírem habilidade, ou ate mesmo por não considerarem importante a espacialização das informações e/ou conteúdos das aulas.

\section{A GEOGRAFIA AMBIENTAL E O PARADIGMA SISTÊMICO}

Esta corrente se materializa na segunda metade do Século XX a partir da década de 1980 na U.R.S.S e França. Tendo o soviético Sotchava, e os franceses Bertrand e Tricart. 
Neste período cresce o uso e aplicação da Cartografia temática e do Geoprocessamento. Na cartografia tivemos o crescimento da Linha da Comunicação Cartográfica.

Claval (2006) coloca que a nova geografia física põe, então, em termos adaptados às situações do mundo contemporâneo, com destaque para o problema das relações do homem e do ambiente. A análise das relações homem-meio ganha destaque com as técnicas de teledetecção, os sistemas de informação geográfica em parceria com os progressos da informática colocam a disposição dos apaixonados pela temática base de dados atualizados e de uma riqueza de detalhes que não fora possível outrora.

A Semiologia como Teoria Geral dos Signos também teve papel significativo no desenvolvimento teórico da Cartografia, dando origem à Semiologia Gráfica. Como linguagem cartográfica, fundamenta-se em uma ciência denominada semiótica, que tem por objeto de investigação todas as linguagens, em especial a dos signos. Signos são componentes linguísticos do sistema de informação cartográfica. Os trabalhos que mais se destacaram foram os do francês J. Bertin (1967) ele sistematiza a linguagem gráfica como um sistema de símbolos gráficos com significado e significante. Os significantes são as variáveis visuais, utilizadas para transcrever as relações entre os dados. As variáveis visuais são: tamanho, valor, textura, cor, orientação e forma.

Bertin foi o primeiro pesquisador a organizar um quadro de variáveis visuais, com as propriedades perceptivas da linguagem gráfica. Ele enfatizou a transcrição da linguagem escrita para a visual, considerando as relações apresentadas entre os dados. Assim a sistematização de tais relações e sua representação gráfica são o ponto de partida na caracterização da linguagem gráfica.

A Semiologia Gráfica começa a aparecer nas pesquisas do Brasil por volta dos anos de 1980 com a tradução de um artigo de Bertin (1980) na Revista Brasileira de Geografia, no qual propõe uma orientação direcionada aos pesquisadores e usuários de mapas e gráficos. Os trabalhos de Marcelo Martinelli da USP tiveram grandes contribuições para a Geografia brasileira.

O programa de Pós-Graduação em Geografia Humana da USP teve grande contribuição com as pesquisas de Martinelli com a linha de Cartografia Temática. Archela (1999) destaca três etapas no desenvolvimento das pesquisas em Semiologia Gráfica no Brasil. Primeira fase de 1980 a 1984 caracteriza-se pela introdução das bases deste enfoque, realizada através de artigos em periódicos de circulação nacional em especial a Revista Brasileira de Geografia do IBGE. Segunda fase de 1985 a 1989 considerado pela autora como de grande produção 
científica, principalmente de artigos e trabalhos em eventos. Terceira fase de 1989 a 1995 apresentou um grande número de dissertações de mestrado baseados na semiologia gráfica como metodologia de ensino de geografia.

\section{A GEOGRAFIA HUMANÍSTICA E O PARADIGMA DA FENOMENOLOGIA}

Moreira (2008) afirma que a fenomenologia é definida como a filosofia das essências e que sua origem moderna se deve a Edmund Husserl. A fenomenologia husserliana tem, de um lado, fortes vínculos com a filosofia de vida, de Wilhelm Dilthey, dela extraindo o conceito do real vivido e, de outro com a filosofia neokantiana, suas contemporâneas de onde extrai o conceito de essência. $\mathrm{O}$ autor evidencia ainda o percurso da fenomenologia dentro de algumas tendências da geografia contemporânea, segundo ele é a percepção ambiental a porta de entrada das correntes de geografia no universo da fenomenologia husserliana, numa sequencia que da geografia da percepção vai para a geografia humanística e desta para a geografia cultural, o fundamento fenomenológico vindo a aparecer mais como um projeto que como um fato efetivado.

Moreira (2008) destaca que a fenomenologia huserliana chega a geografia também nos anos1970. Porém não como uma fenomenologia das essências, mas como uma fenomenologia existencial, uma visão da fenomenologia mais afeiçoada à filosofia de Merleau-Ponty. Perfilam no seu terreno a Geografia da Percepção, a Geografia Humanistica e a Geografia Cultural, além da Geografia Histórica, quatro versões derivadas das matrizes norteamericanas criadas por Sauer, aprofundadas por David Lowenthal nos anos 1960 e dimensionadas por Yi-fu Tuan nos anos 1970, com estes últimos chegando a matriz fenomenológica.

Holzer (2003) coloca que ainda na primeira metade da década de 1970 dois nomes foram importantes para a construção da identidade da geografia humanística, a saber: Tuan e Buttimer ao introduzirem os conceitos de lugar e mundo vivido. No entanto, grande parte da literatura nacional destaca que a geografia humanística consolida-se como corrente da geografia a partir da década de 1980 na França e Estados Unidos. Com Paul Claval e Yi-fu Tuan respectivamente.

Na cartografia tivemos o crescimento da linha da Percepção e representação cognitiva do espaço. Esta Corrente teórica da Cartografia Cognitiva teve no Brasil a contribuição da 
Psicologia Genética de Jean Piaget. Trabalhos como o de Lívia de Oliveira marcaram o início dos trabalhos desta linha.

A Teoria da Cognição como método cartográfico envolve operações mentais lógicas como a comparação, análise, síntese, abstração, generalização e modelização cartográfica. Segundo Archela e Archela (2002) nesta corrente o mapa é considerado como uma variável de informações, dependendo das características do usuário.

Esta corrente foi desenvolvida a partir da Psicologia, trouxe grandes avanços para a Cartografia, tanto no processo de mapeamento, em que o cartógrafo passou a ter uma preocupação maior com as características do usuário, como no processo de leitura, no qual o mapa passou a ser um instrumento para a aquisição de novos conhecimentos sobre a realidade representada. Dentre as contribuições desta corrente para a cartografia, destaca-se a cartografia escolar e a criação dos mapas mentais e da alfabetização cartográfica.

\section{CONCLUSÃO}

Acredita-se que seja insuficiente em poucas linhas traçar o perfil da Geografia a partir de suas correntes de pensamento e estabelecer uma relação entre a produção do conhecimento geográfico e a utilização da Cartografia como forma de representação deste. Nas investigações teóricas realizadas para produção deste trabalho fica evidente que as correntes apoiadas no positivismo embora demonstrem uma preocupação maior na caracterização do espaço geográfico, é pouco expressiva a ênfase dado a utilização da cartografia embora seja utilizada, tanto nas obras clássicas quanto nas obras mais recentes que fazem referencias as características destas correntes.

Percebe-se que a partir da nova geografia a cartografia começa a fazer parte dos estudos geográficos como forma de representação dos dados. Talvez seja pelo fato dos investimentos sucessivos feitos pelas potências do período, a saber, U.R.S.S e Estados Unidos, neste foram lançados vários satélites e a tecnologia espacial ganha destaque. No entanto é a partir doa anos de 1970 que estas tecnologias chegam de fato através dos SIG's, do Sensoriamento Remoto e Cartografia Digital.

O uso de imagens de satélites, GPS, fotografias aéreas e mais recentemente dos VANT's tem contribuído de forma gigantesca para os estudos do espaço geográfico. Mais vale considerar que estas tecnologias não resolvem o problema maior na construção de 
conhecimentos significativos. Pois são os métodos que vão nortear a produção de conhecimento nos diversos campos da geografia.

O mapa não é apenas uma descrição da realidade, mas, em sentido literal, representa um retrato de uma realidade. Os mapas que elaboramos, por intermédio dos vários Softwares SIG, são propositalmente seletivos, pois representamos no mapa apenas os aspectos que nos interessa, desprezamos todas as divergências entre os aspectos representados.

Um dado importante a ser considerado é que as correntes teóricas da cartografia desenvolvidas a partir da década de 1960, independente da terminologia recebida têm em comum o sistema de análise, a saber: a realidade, o criador de mapas, o usuário de mapas e imagem da realidade expressa através do mapa. Variando apenas o veículo de informação através da modelização, da semiologia ou a cognição.

\section{REFERÊNCIAS}

ALMEIDA, R. D. de. Pesquisas em Cartografia Escolar. In: Boletim Paulista de Geografia. n. 90. v. 2. São Paulo: AGB, 2010. p. 97-107.

ANDRADE, M. C. de. Geografia, ciência e sociedade: uma introdução à análise do pensamento geográfico. São Paulo: Atlas, 1987.

ARCHELA, R. S.; ARCHELA, E. Síntese Cronológica da Cartografia no Brasil. Portal da Cartografia. Londrina, v. 1, n. 1, mai./ago., p. 93-110, 2008. Disponível em: http://www.uel.br/revistas/uel/index.php/portalcartografia. Acesso em 19.06.14.

ARCHELA, R. S.; ARCHELA, E. Correntes da Cartografia Teórica e seus reflexos na pesquisa. Geografia, v. 11, n. 2. Jul./dez., 2002.

BRZEZINSKI, I.; GARRIDO, E. Estados da arte sobre formação de professores nos trabalhos apresentados no GT 8 da ANPEd: 1990-1998. In: REUNIÃO ANUAL DA ASSOCIAÇÃO NACIONAL DE PÓS-GRADUAÇÃO E PESQUISA EM EDUCAÇÃO - ANPEd, 22., Caxambu, 1999. Anais. Caxambu, MG, 1999. 1CD

COSTA, F. R. da; ROCHA, M. M. Geografia: conceitos e paradigmas - apontamentos preliminares. Revista GEOMAE, Campo Mourão, PR, v. 1, n. 2, p. 25-56, $2^{\circ}$ semestre de 2010.

CORREA, R. L. Reflexões sobre Paradigmas, Geografia e Contemporaneidade. Revista da ANPEGE, v. 7, n. 1, número especial. p. 59-65, out. 2011.

CLAVAL, P. História da Geografia. Tradução de José Braga Costa. Lisboa: Edições 70, 2006.

FERREIRA, N. S. de A. As pesquisas denominadas "estado da arte". Educação \& Sociedade, ano XXIII, n ${ }^{\circ}$ 79, Agosto/2002.

GIRARDI, E. P. Proposição teórico-metodológica de uma cartografia geográfica crítica e sua aplicação no desenvolvimento do atlas da questão agrária brasileira. Presidente 
Prudente, SP, 2008. 347 f. Tese (Doutorado em Geografia). Faculdade de Ciência e Tecnologia da Universidade Estadual Paulista, 2008.

GOMES, H. Reflexões sobre Teoria e Crítica em geografia. Goiânia: CEGRAF/UFG, 1991.

GUERRA, E. V.; COSTA, N. da S. Geografia brasileira: novas e velhas leituras sobre Ratzel. Revista de Geopolítica, Natal. v. 3, n. 2, p. 220-229, jun./dez. 2012.

MOREIRA, R. O Pensamento Geográfico Brasileiro: as matrizes clássicas originais. São Paulo: Contexto, 2008. (Volume 1).

MOREIRA, R. Para Onde Vai o Pensamento Geográfico? Por uma epistemologia crítica. São Paulo: Contexto, 2008.

MORMUL, N. M.; ROCHA, M. M. Breves considerações acerca do pensamento geográfico: elementos para análise. Geografia Ensino e Pesquisa, v. 17, n. 3, set./dez., p. 64-78, 2013.

PATTISON, William D. As quatro tradições da geografia. Boletim de Geografia Teorética, v. 7, n. 13, 1977. p. 101-110.

SIMIELLI, M. E. R. Cartografia no Ensino Fundamental e Médio. In: CARLOS, A. F. A. (Org.). A Geografia em Sala de Aula. 5. ed. São Paulo: Contexto, 2003.

THERRIEN, J., \& NÓBREGA-THERRIEN, S. Os trabalhos científicos e o estado da questão: reflexões teórico-metodológicas. Estudos em avaliação educacional, v.15, n.30, jul.-dez. 2004. 